\title{
URGENSI TECHNICAL SKILL BAGI TENAGA KERJA KONSTRUKSI DALAM ERA INDUSTRI 4.0
}

\author{
Blima Oktaviastuti ${ }^{1}$, Riana Nurmalasari ${ }^{2}$, dan Fifi Damayanti ${ }^{3}$ \\ ${ }^{1}$ Program Studi Teknik Sipil, Fakultas Teknik, Universitas Tribhuwana Tunggadewi, Malang \\ ${ }^{2}$ Jurusan Teknik Mesin, Fakultas Teknik, Universitas Negeri Malang \\ ${ }^{3}$ Program Studi Teknik Sipil, Fakultas Teknik, Universitas Tribhuwana Tunggadewi, Malang \\ E-mail: blima.oktavia90@gmail.com,riana.nurmalasari.ft@um.ac.id,fifidamayanti197408@yahoo.co.id
}

\begin{abstract}
ABSTRAK: Tulisan ini bertujuan untuk memaparkan kajian tentang: (1)tenaga kerja konstruksi; (2) technical skill; dan (3)pentingnya technical skill bagi tenaga kerja konstruksi. Kesimpulan yang diperoleh dari kajian ini bahwa, tenaga kerja yang kompeten secara langsung memiliki technical skill mumpuni dalam melaksakan pekerjaannya. Perkembangan pembangunan infrastruktur di Indonesia semakin banyak membutuhkan tenaga kerja dengan technical skill mumpuni sesuai kompetensi keahliaannya. Kebutuhan tenaga kerja konstruksi menjadi hal yang utama. Perlunya pengembangan dan penerapan technical skill sejak di bangku sekolah atau lembaga pelatihan, diharapkan dapat membiasakan serta membekali siswa dengan technical skill sebelum memasuki dunia kerja.
\end{abstract}

\section{Kata Kunci: Konstruksi; Tenaga Kerja; Technical Skill}

\section{PENDAHULUAN}

Kemajuan ilmu pengetahuan dan teknologi dewasa ini mengalami perkembangan pesat. Hal ini turut andil dalam perkembangan industri atau jasa konstruksi Indonesia secara tidak langsung. Sebagai contoh banyak proyek pembangunan yang dilaksanakan oleh pemerintah maupun pihak swasta dengan berbagai teknologi dan inovasi yang ditawarkan. Rencana Pembangunan Jangka Panjang Nasional (RPJPN) tahun 2005-2025 juga diarahkan untuk lebih memantabkan pembangunan secara menyeluruh di berbagai bidang (Kementerian Bappenas, 2017).

Penekanan pembangunan bertujuan untuk mencapai daya saing kompetitif pada perekonomian dengan berlandaskan keunggulan Sumber Daya Manusia (SDM) dan Sumber Daya Alam (SDA) berkualitas, dengan diimbangi kemampuan IPTEK yang terus meningkat. Konstruksi juga merupakan sektor perekonomian yang sangat penting untuk menghasilkan suatu produk bangunan, baik sebagai infrastruktur maupun properti (Taufik, A.I., 2012:216).

Peningkatan kualitas jasa konstruksi telah tertuang dalam Undang-Undang Nomor 18 Tahun 1999 tentang Jasa Konstruksi (UUJK). Perkembangan pesat tersebut diharapkan dapat mengembangkan peran serta jasa konstruksi nasional agar meningkatkan kualitas hasil kerja konstruksi. Salah satu faktor peningkatan kualitas tersebut dengan adanya peran serta tenaga kerja konstruksi yang kompeten.

Memasuki era industri 4.0 secara tidak langsung memberikan dampak signifikan pada perkembangan ekonomi di Indonesia. Sektor jasa konstruksi juga tidak lepas terkena dampaknya. Peran serta tenaga kerja menjadi salah satu kunci keberhasilan pelaksanaan suatu proyek jasa konstruksi. Berdasarkan artikel medan bisnis oleh Pasaribu (2016), dibutuhkan sedikitnya 750.000 orang tenaga kerja konstruksi bersertifikat ahli muda, madya dan utama serta tenaga kerja konstruksi bersertifikat terampil kelas satu, kelas dua dan tiga.
Dilanjutkan artikel sindo oleh Glienmourinsie (2015) menyatakan bahwa Indonesia memiliki jumlah tenaga kerja konstruksi yang cukup banyak, namun sebagian besar belum bersertifikasi yang mengakibatkan investor asing lebih memilih mendatangkan tenaga kerja dari luar negeri. Data tersebut menunjukkan bahwa Indonesia masih kekurangan tenaga kerja yang ahli. Tenaga kerja Indonesia harus memiliki technical skill yang mumpuni agar dapat bersaing dengan tenaga kerja luar negeri.

Berdasarkan uraian permasalahan diatas, maka tulisan ini bertujuan untuk memaparkan kajian tentang: (1) pekerja konstruksi, (2) technical skill, dan (3) pentingnya technical skill bagi tenaga kerja konstruksi.

\section{TENAGA KERJA KONSTRUKSI}

Simanjuntak (1998), tenaga kerja mencakup penduduk yang sudah atau sedang bekerja, yang sedang mencari pekerjaan dan yang melakukan kegiatan lain seperti bersekolah dan mengurus rumah tangga. Husni, L. (2003) menyatakan bahwa tenaga kerja adalah penduduk dalam usia kerja (berusia 15-64 tahun) atau jumlah penduduk dalam suatu negara yang dapat memproduksi barang dan jasa jika ada permintaan terhadap tenaga kerja mereka dan jika mereka mau berpartisipasi dalam aktifitas tersebut. Pengertian tenaga kerja menurut Undang-undang Republik Indonesia No. 13 Tahun 2003 tentang ketenagakerjaan adalah setiap orang yang mampu melakukan pekerjaan guna menghasilkan barang dan/atau jasa baik untuk memenuhi kebutuhan sendiri maupun masyarakat.

Saputri dan Rejekiningsih (2011) tenaga kerja dibagi dalam dua kelompok yaitu angkatan kerja dan bukan angkatan kerja. Angkatan kerja adalah penduduk dalam usia kerja yang terlibat atau berusaha untuk terlibat dalam kegiatan produktif yaitu memproduksi barang dan jasa. Angkatan kerja terdiri dari golongan bekerja serta golongan menganggur dan mencari pekerjaan. Bukan angkatan kerja adalah penduduk dalam usia kerja yang tidak bekerja, tidak mempunyai pekerjaan dan sedang 
tidak mencari pekerjaan. Bukan angkatan kerja terdiri dari golongan yang bersekolah, golongan yang mengurus rumah tangga dan golongan lain-lain atau penerima pendapatan. Ketiga golongan dalam kelompok ini sewaktu-waktu dapat menawarkan jasanya untuk bekerja. Oleh sebab itu, kelompok ini sering juga dinamakan sebagai angkatan kerja potensial (potensial labor force).

Ukuran produktivitas dalam pekerjaan yang sering diamati adalah pelakunya (tenaga kerja). Haryadi, B. (2010), kompetensi tenaga kerja konstruksi harus dapat ditunjukan secara realitas, legalitas dan akademik, serta tenaga kerja harus memiliki kompetensi dan bersertifikat, sedangkan untuk meningkatkan kompetensi tenaga kerja konstruksi dapat dilakukan dengan banyak melakukan pelatihan-pelatihan.

Berdasarkan UU No.13 Tahun 2003 Tentang Ketenagakerjaan, fungsi dan tugas-tugas tenaga kerja berdasarkan kehaliannya meliputi: (1)Mandor adalah orang yang mempunyai keahlian dalam bidang tertentu sesuai dengan jenis pekerjaan tertentu. Mandor membawahi langsung pekerja-pekerja atau tukangtukang; (2)Kepala tukang adalah orang yang mempunyai keahlian dalam bidang pertukangan untuk jenis pekerjaan tertentu dan memberi petunjuk-petunjuk kepada para tukang yang berhubungan dengan jenis pekerjaan tersebut; (3)Tukang adalah orang yang langsung mengerjakan pekerjaan dilapangan dalam bidang tertentu sesuai petunjuk kepala tukang. Orang-orang ini biasanya memiliki sedikit keterampilan; (4)Pekerja (buruh) adalah orang yang membantu tukang atau kepala tukang untuk semua jenis pekerjaan tanpa harus memiliki keahlian atas pekerjaan tertentu.

Pekerjaan di bidang konstuksi disamping menghasilkan jasa (misal menggambar denah bangunan) juga dapat menghasilkan barang (misal material bangunan keramik). Tidak hanya di bidang konstruksi, pekerjaan yang lain juga selalu membutuhkan skill yang mumpuni. Jika tenaga kerja tidak memiliki bekal skill yang mumpuni, maka akan kalah saing dengan tenaga kerja yang memiliki skill. Skill dijadikan tolok ukur utama dikarenakan dapat meningkatkan produktivitas suatu pekerjaan. Mengingat sudah memasuki era industri 4.0, maka tidak mengherankan jika persaingan dalam mencari pekerjaan semakin selektif, utamanya untuk pekerja konstruksi.

\section{TECHNICAL SKILL}

Technical skill merupakan bagian dari kompetensi yang harus dimiliki oleh tenaga kerja. Undang-Undang (UU) No. 13 tahun 2003 tentang Ketenagakerjaan menyebutkan bahwa kompetensi adalah kemampuan kerja setiap individu yang mencakup aspek pengetahuan, keterampilan dan sikap kerja yang sesuai dengan standar yang ditetapkan. Hakikat kompetensi merupakan perpaduan dari pengetahuan, keterampilan, nilai dan sikap yang direfleksikan dalam kebiasaan berpikir dan bertindak.

Mulyasa (2013:67) menggolongkan beberapa aspek yang terkandung dalam konsep kompetensi meliputi: (1) pengetahuan (knowledge); (2) pemahaman (understanding); (3) kemampuan (skill); (4) nilai (value); (5) sikap (attitude); dan (6) minat (interest).

Maman (Fernando,dkk., 2015:586) technical skill merupakan kecakapan menangani atau memecahkan suatu masalah melalui penggunaan peralatan, prosedur, metode, dan teknik dalam proses operasional, terutama menyangkut dengan pekerjaan yang berhubungan alat-alat yang harus digunakan dalam menyelesaikan pekerjaan. Technical skill diperlukan untuk menangani gangguan pada pekerjaan yang disebabkan oleh kerusakan peralatan, kelemahan kualitas, kecelakaan, keterbatasan material, dan masalah-masalah koordinasi.

Nurmalasari, R., dkk. (2019); Oktaviastuti, B., dkk. (2018) Sekolah Menengah Kejuruan (SMK) memberikan pelajaran berupa teori dan praktek sesuai kompetensi yang telah dipilih oleh siswa. Keberadaannya sangat membantu dalam membekali calon tenaga kerja konstruksi, disamping adanya balai latihan kerja yang dinaungi oleh pemerintah.

\section{PENTINGNYA TECHNICAL SKILL BAGI TENAGA KERJA KONSTRUKSI}

Oktaviastuti, B., dkk. (2016) kepemilikan tenaga kerja yang kompeten dan memiliki technical skill yang mumpuni, secara tak langsung meningkatkan produktivitas suatu negara. Tenaga kerja dengan technical skill yang kompeten sesuai bidangnya, memiliki nilai lebih dibandingkan dengan yang tidak.

Tenaga kerja yang memiliki technical skill, cenderung memiliki tingkat produktivitas lebih unggul daripada yang tidak memiliki technical skill. Hal ini secara langsung dapat memberikan keuntungan terhadap industri jasa konstruksi. Oleh karenanya, technical skill sangat dibutuhkan tenaga kerja saat melaksanakan pekerjaannya. Jika tenaga kerja tidak memiliki technical skill, sudah jelas akan kalah saing dengan yang memiliki. Apalagi di era industri 4.0 dengan saingan yang tidak hanya berasal dari dalam negeri.

\section{KESIMPULAN}

Technical skill dapat diperoleh melalui pendidikan, pelatihan motivasi, update teknologi, dan berbagai usaha kelompok lainnya. Penerapan technical skill pada sektor jasa konstruksi, secara tidak langsung akan berpengaruh pada peningkatan produktivitas tenaga kerja. Tenaga kerja yang kompeten akan dibekali technical skill mumpuni sesuai keahliannya. Pembekalan dapat melalui balai latihan kerja dan menambah kuota pendidikan di bidang kejuruan. Di Indonesia sendiri, masih perlu pengembangan dan penerapan technical skill sejak di bangku sekolah (utamanya untuk sekolah kejuruan).

\section{DAFTAR PUSTAKA}

Fernando, Z.A., Inra, A., dan Yustisia, H. 2015. Kesiapan Mahasiswa Program Studi Teknik Sipil dan Bangunan di Bidang Teknik Sipil. CIVED ISSN 2302-3341. 3(1): 584-590 
Glienmourinsie, Disfiyant. 2015. Sebagian Besar Tenaga Kerja Konstruksi Belum Bersertifikasi, (Online), https://ekbis.sindonews.com, diakses 10 November 2020.

Haryadi, Bada. 2010. Kompetensi Tenaga Kerja Konstruksi Dalam Menghadapi Era Liberalisasi. Jurnal Inersia. 6(1): 33-40.

Husni, L. 2003. Hukum Ketenagakerjaan Indonesia. Jakarta: PT. Raja Grafindo Persada.

Kementerian Bappenas. 2017. Dokumen Perencanaan dan Pelaksanaan RPJPN 2005-2025. (Online) https://www.bappenas.go.id, diakses 15 November 2020 .

Kementerian PUPR RI. 2015. Pasar Konstruksi Indonesia Besar, Jumlah Insinyur Masih Kurang. (online), http://www.pu.go.id., diakses 12 November 2020.

Kemenperin RI. 2003. Undang-Undang Keternagakerjaan: Pasal 86 Nomor 13.

Kemenperin RI. 2003. Undang-Undang Keternagakerjaan: Pasal 1 Nomor 13 ayat 10

Mulyasa. 2013. Pengembangan dan Implementasi Kurikulum 2013. Bandung: Remaja Rosdakarya.

Nurmalasari, R., Oktaviastuti, B., dan Nafiah, A. 2019. The Role and Teacher's Understanding in Implementing Curriculum on Vocational High School. JPP (Jurnal Pendidikan dan Pembelajaran). 26(2): 57-59.

Oktaviastuti, B., Dardiri, A., Nindyawati, and Nurmalasari, R. 2016. The correlation between industrial support and vocational attitude toward the increasing of student's technical skill on building drawings engineering. Jurnal AIP Conference Proceedings. 1778(1): 030039.

Oktaviastuti, B., dan Indana, L. 2018. Warna Pembelajaran PSG: Peningkatan Technical Skill Siswa SMK Sebagai Kebutuhan Dunia Kerja. Jurnal Bangunan. 23(1).

Pasaribu, B. 2016. Dibutuhkan 750.000 Tenaga Kerja Konstruksi Bersertifikat. (online), http://www.medanbisnisdaily.com., diakses 10 November 2020.

Saputri, O.D. dan Rejekiningsih, T.W. 2011. Analisis Penyerapan Tenaga Kerja Di Kota Salatiga. (Online). http.//www.eprints.undip.ac.id., diakses 12 November 2020.

Simanjuntak, P.J. 1998. Pengantar Ekonomi Sumber Daya Manusia. Jakarta: Fakultas Ekonomi Universitas Indonesia.

Taufik, A.I. 2012. Pembaharuan Regulasi Jasa Konstruksi dalam Upaya Mewujudkan Struktur Usaha yang Kokoh, Andal, Berdaya Saing Tinggi dan Pekerjaan Konstruksi yang Berkualitas. Jurnal Rechts Vinding Media Pembinaan Hukum Nasional, 1(2): 215-235.

Undang-Undang Nomor 18 Tahun 1999 tentang Jasa Konstruksi (UUJK). 
Jurnal Rekayasa Tenik Sipil Universitas Madura Vol. 5 No. 2 Desember 2020 ISSN 2527-5542

Halaman Ini Sengaja Dikosongkan 